\title{
Crassicauda boopis in a fin whale (Balaenoptera physalus) ship-struck in the eastern North Atlantic Ocean
}

\author{
LAETITIA LEMPEREUR ${ }^{1}$ *, MORGAN DELOBELLE ${ }^{1}$, MARJAN DOOM $^{2}$, \\ JAN HAELTERS ${ }^{3}$, ETIENNE LEVY ${ }^{4}$, BERTRAND LOSSON ${ }^{1}$ and THIERRY JAUNIAUX ${ }^{4}$ \\ ${ }^{1}$ Faculty of Veterinary Medicine, University of Liège, Center for Fundamental and Applied Research for Animal and \\ Health (FARAH), Laboratory of Parasitology and Parasitic Diseases, Quartier Vallée 2, Av de Cureghem, 6 B43a-4000 \\ Liège, Belgium \\ ${ }^{2}$ Faculty of Veterinary Medicine, Department of Morphology, University of Ghent, Salisbuylaan 133, 9820 Merelbeke, \\ Belgium \\ ${ }^{3}$ Royal Belgian Institute of Natural Sciences, Operational Directorate Natural Environment, 3de en 23ste \\ Linieregimentsplein, B-8400 Ostend, Belgium \\ ${ }^{4}$ Faculty of Veterinary Medicine, University of Liège, Center for Fundamental and Applied Research for Animal and \\ Health (FARAH), Pathology Unit, Quartier Vallée 2, Av de Cureghem, 6 B43a-4000 Liège, Belgium
}

(Received 23 fanuary 2017; revised 14 June 2017; accepted 14 fune 2017)

\begin{abstract}
SUMMARY
On 9 November 2015, a juvenile male fin whale of $11.60 \mathrm{~m}$ length was observed on the bulb of a merchant vessel in the Channel Terneuzen - Ghent (The Netherlands - Belgium). A severe parasitosis was present in the right heart ventricle and caudal caval vein. Parasites were identified as Crassicauda boopis based on macroscopic and microscopic observations. The sequence of the 18S rRNA gene obtained from the parasite samples was 100\% similar to the sequence of the $18 \mathrm{~S}$ rRNA gene from Crassicauda magna available on GenBank. While adults of C. boopis and C. magna are morphologically distinct and found at different locations in the body, the molecular analysis of the $18 \mathrm{~S}$ rRNA gene seems insufficient for reliable species identification. Although numerous C. boopis were found, the cause of death was identified as due to the collision with the ship, as suggested by the presence of a large haematoma, and the absence of evidence of renal failure. The young age of this whale and the absence of severe chronic reaction may suggest that the infestation was not yet at an advanced chronic stage.
\end{abstract}

Key words: Crassicauda boopis, fin whale, kidney, caudal caval vein.

\section{INTRODUCTION}

The fin whale (Balaenoptera physalus) is a marine mammal belonging to the suborder of baleen whales (Cetacea, Mysticeti). It is the second-largest animal on earth after the blue whale (Balaenoptera musculus). Although fin whales are found in all major oceans and a number of seas, from polar to tropical waters, it is rare in the southern North Sea, and in most cases solitary animals are seen (Camphuysen and Peet, 2006). It feeds by filtering a large volume of seawater, enabling to harvest large zooplankton mainly Northern krill (Meganyctiphanes norvegica) but also small schooling fish such as herring (Clupea harengus), squid and crustaceans including copepods (Lambertsen, 1986; Ruys and Soulier, 2013). Cetaceans serve as hosts to numerous parasites, including many nematode species such as crassicaudids (Nematoda, Spirurida) (Lambertsen, 1986). Crassicauda spp. occur under the skin or in deep tissues of the

* Corresponding author: Faculty of Veterinary Medicine, Laboratory of Parasitology and Parasitic Diseases, University of Liège, Quartier Vallée 2, Av de Cureghem, 6 B43a, 4000 Liège, Belgium. E-mail: llempereur@ulg. ac.be mammary glands, in cranial sinuses and the urogenital system (Geraci and St. Aubin, 1987; Lambertsen, 1986; Zucca et al. 2004; Jabbar et al. 2015). Three nominal species of adult Crassicauda have been described in the urogenital system of the fin whale, namely $C$. crassicauda, $C$. boopis and $C$. pacifica (Lambertsen, 1985, 1986). The former is the smallest of the three, and occupies the lower urinary tract (urethra), whereas the latter two infect the kidneys and are considered as taxonomically synonymous as morphologically indistinguishable (Lambertsen, 1985).

Crassicauda boopis (Tetrameridae, Baylis, 1920) is a round worm attaining a length of approximately $1 \cdot 5-2 \mathrm{~m}$. The parasite shows a large anterior part (5 mm wide), which is often observed protruding in the blood flow and an attenuated posterior portion ( $1 \mathrm{~mm}$ wide) traversing the ureteric epithelium and lying free within renal ducts. Larvated eggs are observed and larvae can be found in urine of infected animals (Rees, 1953; Lambertsen, 1985). Of several known crassicaudid infections, those caused by $C$. boopis are highly pathogenic. Infections with adult $C$. boopis can be associated with a marked thrombophlebitis of the vascular system draining the kidneys. The tissue reaction

Parasitology Open (2017), Vol. 3, e9; page 1 of 6. (C) Cambridge University Press 2017. This is an Open Access article, distributed under the terms of the Creative Commons Attribution-NonCommercial-NoDerivatives licence (http://creativecommons.org/licenses/by-nc-nd/ $4.0 /$ ), which permits non-commercial re-use, distribution, and reproduction in any medium, provided the original work is unaltered and is properly cited. The written permission of Cambridge University Press must be obtained for commercial re-use or in order to create a 
can cause multiple obstructions of the primary renal veins. The osmotic stress experienced by the whale in its naturally saline environment is then aggravated by a pathologic stress to the kidneys. Consequently, severe infections with $C$. boopis could reduce blood flow from the kidneys to such a level that the whale succumbs to congestive renal failure. Moreover, the finding of intravascular parasitic masses and associated thrombi supports the possibility of a thromboembolism in crassicaudiosis. This is especially true in case of pulmonary lesions with parasite fragments and mineralized lesions (Lambertsen, 1992).

The life cycle of $C$. boopis is not entirely known yet. It is largely hypothetical based on the pattern of lesions observed, and the frequent report of heteroxenous transmission for marine Spirurida (Lambertsen, 1986; Rhode, 2005). This suggests a somatic migration of $C$. boopis larvae from the gut after their ingestion by the whale. The primary infective route is assumed to involve penetration of the wall of the gastrointestinal tract by $C$. boopis larvae that are ingested by the whale and migration of these larvae up the mesenteric arteries and the aorta (Lambertsen, 1986; Díaz-Delgado et al. 2016). Entry of C. boopis into the kidneys, its definitive habitat, could well involve larval movements via two different routes: from the aorta directly within the wall of the arterial system or by the arterial blood flow. Thereafter, the developing larvae would have easy access to both the urinary ductwork and the renal veins. Finally, by further developing in the venous system of the kidney, the adult stage could then extend from the urinary ducts to the caval vein. Persistent larvae migrans are suggested by lesions induced by developing $C$. boopis larvae that are not carried by the arterial bloodstream to the kidneys but rather lodge in the capillaries of other tissues (Lambertsen, 1992).

The finding of larvae and larvated eggs in the urine suggest that the primary portal of exit is the urinary tract. The presence of eggs in the pulmonary airspace is also compatible with low levels of shedding via the whale's blow (Lambertsen, 1986).

Krill, such as $M$. norvegica, which is the principal prey of fin whales in the northern Atlantic Ocean, could potentially play a role as an intermediate host (Lambertsen, 1985; Sigurjonsson and Vikingsson, 1995; William et al. 2009).

The finding of young calves infected with $C$. boopis suggests either a transplacental transmission or the urinary contamination of the environment followed by an oral infection of the calf before being able to feed by itself. Finally, galactogenic transmission cannot entirely be disregarded (Díaz-Delgado et al. 2016).

This paper aims at describing a rarely reported case of $C$. boopis in fin whale and its molecular screening for parasite identification improvement.
MATERIALS AND METHODS

On 9 November 2015, a fin whale was observed on the bulb of a vessel in the Channel Terneuzen Ghent (The Netherlands - Belgium). According to the captain of the vessel, the whale had not been present on the bulb 2 days prior to the observation (Jan Haelters, personal communication). The ship (204 $\mathrm{m}$ long, cruising speed of $18-20 \mathrm{kts}$ ) had sailed from Porto de Santos (Brazil) to Ghent in 12 days. The fin whale was removed from the bulb in the port of Ghent and transported to shore for necropsy (Fig. 1) following a standardized procedure (Jauniaux et al. 2002).

Parasites from veins and kidneys were preserved in $80 \%$ alcohol for morphological and molecular identification. Cephalic and genital regions of the parasite were microscopically investigated after clearing in lactophenol. Renal tissue was preserved in $10 \%$ buffered formaline and embedded in paraffin wax. Sections were stained with haematoxylin and eosin for histopathological examination.

\section{Molecular identification}

Genomic DNA was isolated from 10 worms using DNeasy Blood \& tissue kit (Qiagen, Germany) following the manufacturer's recommendations. The $18 \mathrm{~S}$ rRNA gene was amplified from genomic DNA by PCR using G18S4-F (5'-GCTTGTCTCAA AGATTAAGCC-3') and reverse 136-R (5' TG ATCCTTCTGCAGGTTCACCTAC-3') primers (Nadler et al. 2007; Jabbar et al. 2015).

PCRs were conducted in $25 \mu \mathrm{L}$ volumes containing Taq polymerase master mix (Qiagen, Germany). PCR cycling conditions were $94^{\circ} \mathrm{C}$ for $5 \mathrm{~min}$, then 35 cycles of $94^{\circ} \mathrm{C}$ for $30 \mathrm{~s}, 55^{\circ} \mathrm{C}$ for $30 \mathrm{~s}$ and $72{ }^{\circ} \mathrm{C}$ for $80 \mathrm{~s}$, followed by $72{ }^{\circ} \mathrm{C}$ for $7 \mathrm{~min}$. Amplicons were observed on $2 \%$ agarose gel. A PCR amplifying internal portion of the $18 \mathrm{~S}$ rRNA gene was designed using primers Crassic1160R (5'-CAGGTGAGTTTTCCCGTG TT-3') and reverse Crassic352F (5'-AAACGGCT ACCACATCCAAG-3') in order to facilitate the sequencing. Examination of PCR amplicons was done on a $2 \%$ agarose gel. PCR products were subsequently purified using MinElute PCR purification kit (Qiagen, Germany) and subjected to automated DNA sequencing in both directions (Giga genomic platform, University of Liège). Sequences were aligned using Clustal Omega (http://www.ebi.ac. uk) and a consensus was submitted to Blastn (http://blast.ncbi.nlm.nih.gov).

\section{RESULTS}

\section{Clinical presentation and post-mortem findings}

The fin whale was a juvenile male of $11.60 \mathrm{~m}$ length showing a slight emaciation with a blubber thickness 


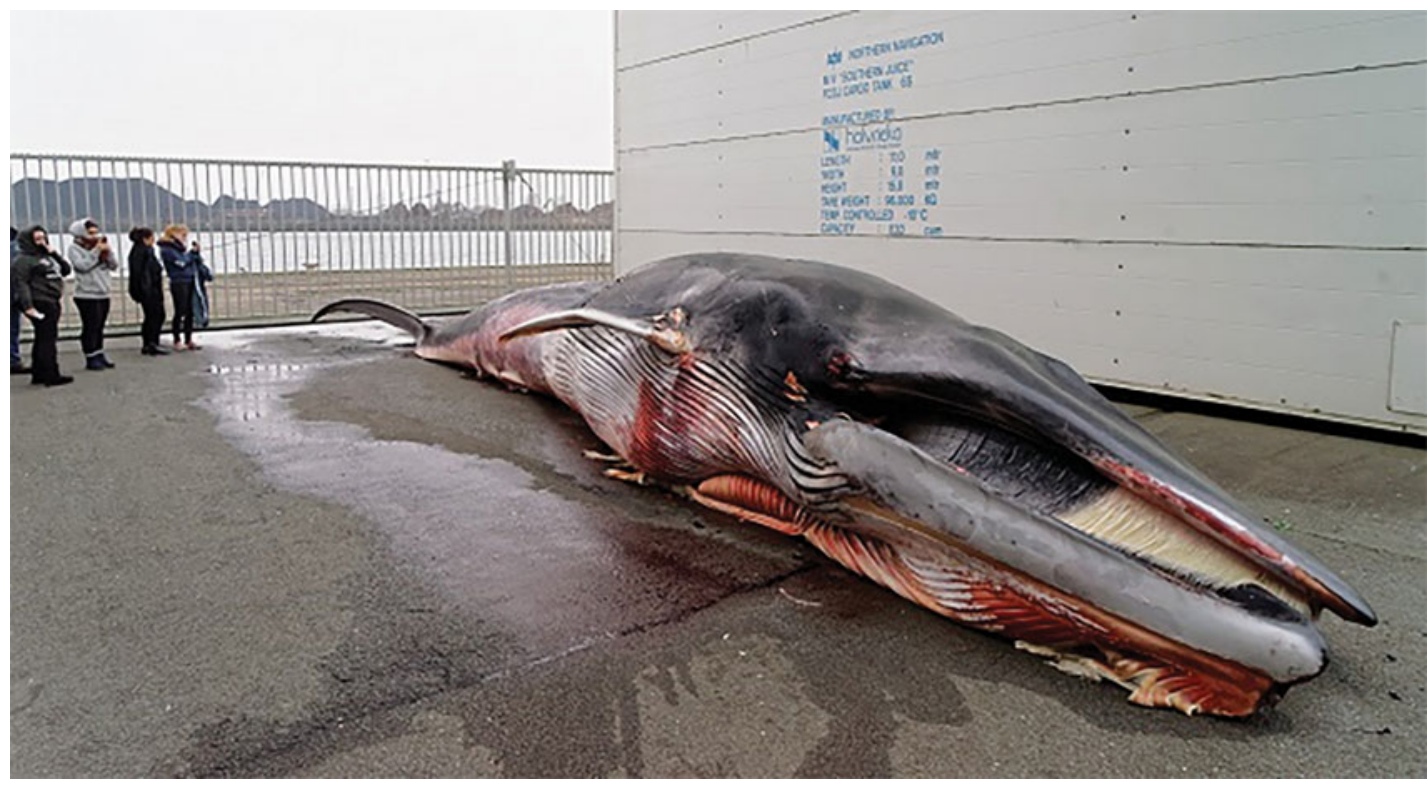

Fig. 1. Fin whale (Balaenoptera physalus) on the necropsy site.

of $50 \mathrm{~mm}$ (dorsal), $35 \mathrm{~mm}$ (median) and $35 \mathrm{~mm}$ (ventral) (Fig. 1). The eyes were clear, with a transparent lens and the presence of gas bubbles, which suggested, together with observation reported by the captain, that the time of the death was about 2-3 days ago. External observations of the body showed an impact zone with cutaneous lacerations of about $1.65 \mathrm{~m}$ wide. When the abdominal cavity was opened, an associated free haemorrhagic and fibrinous liquid was present. An intestinal haematoma of $40 \mathrm{~cm}$ in length was observed at the impact zone. A thrombus was observed in the right lung and parasite fragments were present in the pulmonary vessels (Fig. 2). A severe parasitosis was present in the lumens of the right heart ventricle and the caudal caval vein (Fig 2). These parasites (approximately 50) were white to reddish round worms of approximately $1 \mathrm{~m}$ long and $5 \mathrm{~mm}$ in diameter. A renal thrombosis was also observed, with the presence of round worms of $20 \mathrm{~cm}$ in length and $1 \mathrm{~mm}$ in diameter (Fig. 2).

\section{Microscopic observations}

Several parasites found in the caudal caval vein were observed microscopically. A cephalic extremity was found on a large striated worm portion of $5 \mathrm{~mm}$ in diameter with a tapering apex (Fig. 3). The head was located at the very tip of this tapering section and exhibited a constriction; the mouth bore two lateral lips (Fig. 3). Worms found in the renal veins showed a typical posterior extremity on an attenuated worm section ( $1 \mathrm{~mm}$ in diameter). The posterior extremity of female worms was distinguished by the presence of a constriction before a rectangular end (Fig. 3). No male posterior extremity was observed. Larvated eggs measuring $50 \mu \mathrm{M}$ in length were found on the parasite cuticle (Fig. 4). These observations allowed us to identify two fragments most probably belonging to $C$. boopis. Parasite fragments found in the lungs were not preserved.

Microscopically, significant lesions were located in the kidneys. In the renal thrombosis, a nematode with larvated eggs was observed in an arteriole (Fig. 4). A subacute arteritis and periarteritis was characterized by the infiltration of lymphocytes and macrophages in and around the blood vessel. In the renal interstitial tissue, worms were surrounded by an area of lymphocytes and macrophages with the presence of a multinucleate giant cell (Fig. 4).

\section{Molecular identification}

Amplicons of about $1700 \mathrm{bp}$ and an internal portion of $808 \mathrm{bp}$ were visualized on $2 \%$ agarose gel. A consensus sequence (GenBank KY263809) was made based on sequences obtained from these PCR products and was submitted to Blastn (http://blast. ncbi.nlm.nih.gov) showing 100\% similarity with Crassicauda magna (GenBank KM233410).

\section{DISCUSSION}

Crassicaudiosis is one of the main parasitic diseases of fin whales (Lambertsen, 1986). The difficulties in field sampling, limited possibilities for experimental work and difficulties to observe these specimens in the marine environment make information on $C$. boopis scarce (Lambertsen, 1985; Balbuena and Simpkin, 2014; Jabbar et al. 2015). The life cycle is not yet entirely elucidated, and little is known about potential intermediate hosts. 

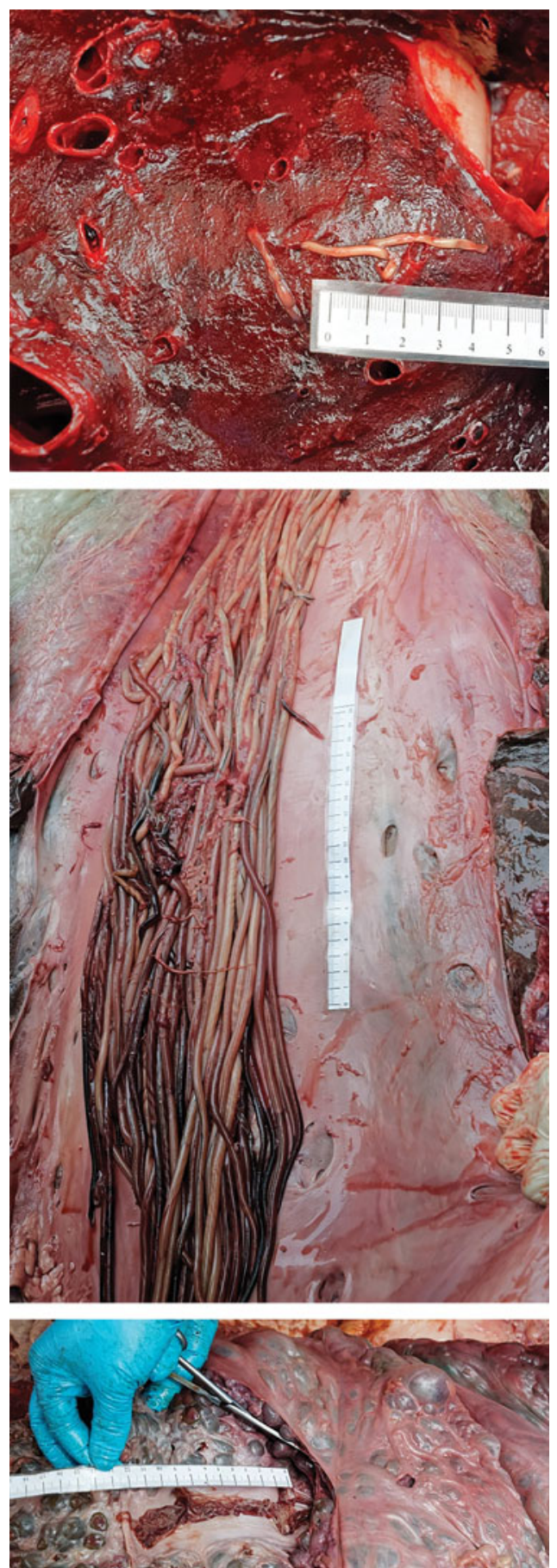

Fig. 2. Nematode segments found in lungs (top), the caudal caval vein (middle) and the renal vein (bottom) of the fin whale.

Moreover, transmission to calves, which are regularly and heavily infested (Lambertsen, 1992), is suspected to be transplacental, whereas galactogenic transmission has to be considered even though up to now no larvae were found in milk or mammary tissue (Díaz-Delgado et al. 2016). Direct transmission to calves by urine contamination was evoked (Lambertsen, 1986), which suggests emission of infective larvae in the environment and therefore a bypass in the need of an intermediate host. This
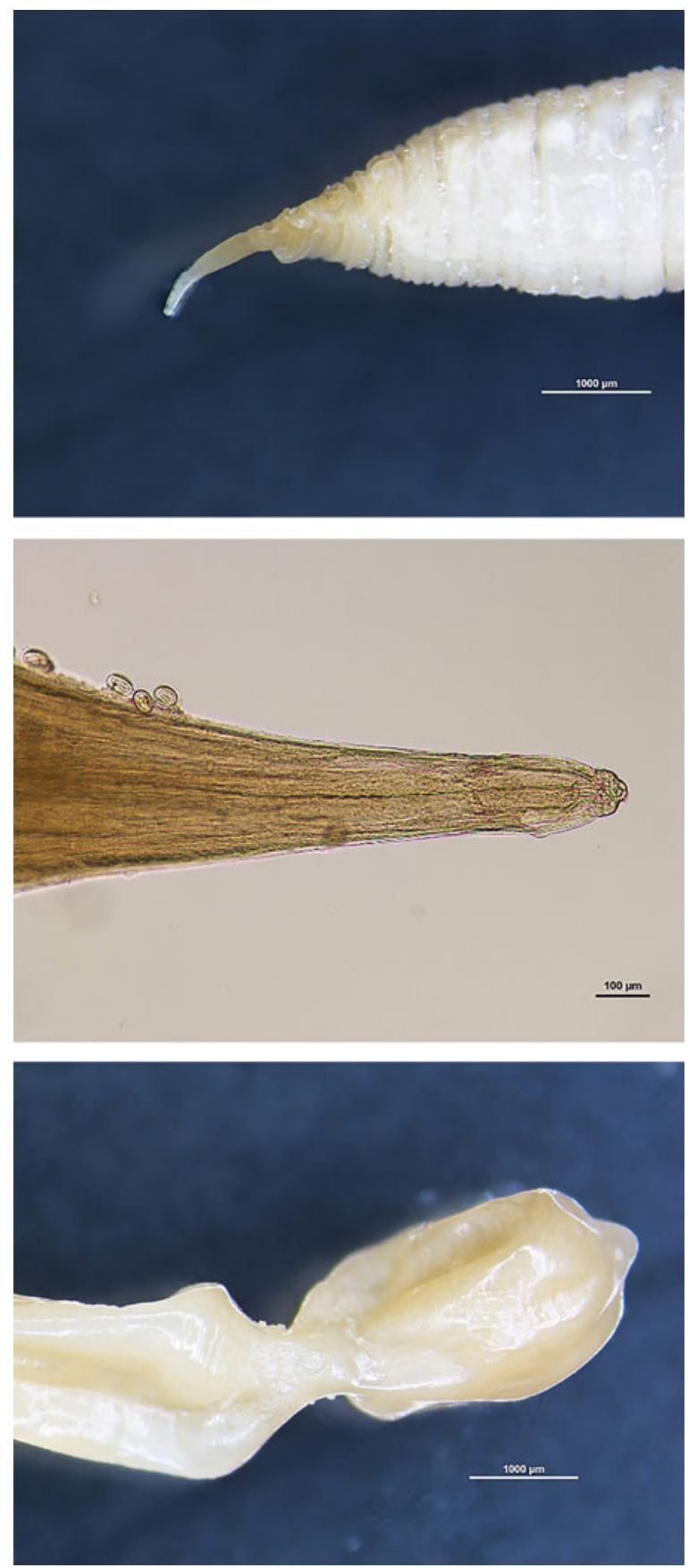

Fig. 3. Anterior extremity $(20 \times)$ (top), $(400 \times)$ (middle) and posterior extremity of female Crassicauda boopis $(20 \times)$ (bottom).

suggestion seems unlikely because of the obvious thick shells of the eggs of $C$. boopis usually encountered in environmentally resistant eggs and the fact that habronematoids are known to use arthropod intermediate hosts consistently (Anderson, 2000).

In this present case, the size of the juvenile fin whale corresponds to a recently weaned fin whale, in which weaning occurs at an age of 6-7 months and a body size of 11-13 m (William et al. 2009). Therefore, the present report supports the theory that infestation could occur transplacentally or during lactation. 

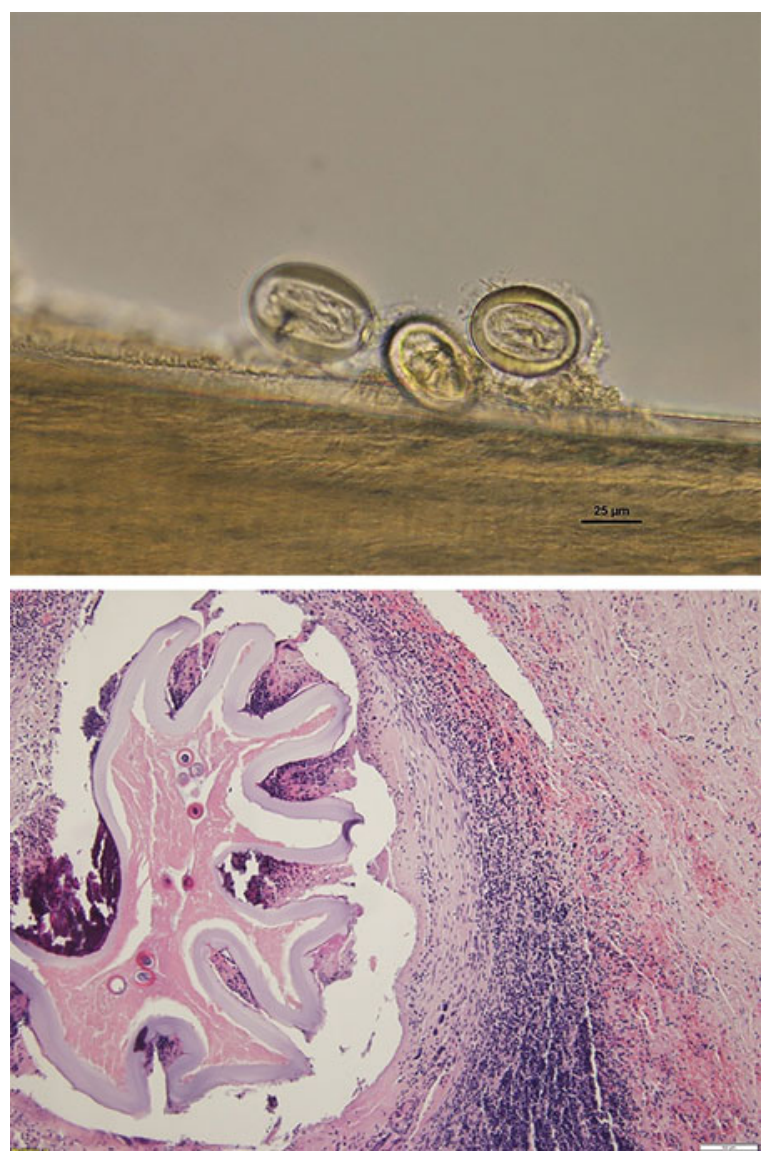

Fig. 4. Larvated eggs of Crassicauda boopis (400×) (top); histopathological examination of renal tissue: nematode with larvated eggs in an arteriole. The subacute arteritis and periarteritis is characterized by infiltration of lymphocytes and macrophages (bottom).

Crassicaudiosis due to $C$. boopis is typically a chronic disease and has proven to be potentially lethal, mainly due to congestive kidney failure, or to cause substantial morbidity in those animals which survive (Lambertsen, 1985, 1992; Jauniaux et al. 2000; Díaz-Delgado et al. 2016). In some individuals, a more acute inflammatory reaction surrounds the parasites with exudate or pus. Lesions associated with $C$. boopis occur less commonly in the lungs, which can contain necrotic fragments of nematodes, as described in this present case, with mineral deposits (Lambertsen, 1992). Although numerous $C$. boopis and lesions similar to those described by Lambertsen (1986) and Jauniaux et al. (2000) were found in the fin whale case presented here, the cause of death could be established as the collision with the ship on the basis of the presence of large haematoma at the impact zone and the absence of evidence of renal failure. The young age of this whale and the absence of severe reaction may suggest that the infestation was not at an advanced chronic stage yet.

Crassicauda genus is represented by large size nematodes with $C$. boopis as the second longest nematode in whales. Consequently, obtaining intact specimens from host tissues is a real challenge and the species is frequently only described from fragments, leading to uncertainty in their identification. Therefore, molecular biology could be useful in the identification of these specimens. Consensus sequence of $18 \mathrm{~S}$ rRNA gene obtained from these present samples was similar to the sequence obtained from parasites found in subcutaneous tissues of a pygmy sperm whale (Kogia breviceps) and identified as C. magna (Jabbar et al. 2015). Additionally, this sequence was similar to the partial sequence of a worm located in the kidney of a Cuvier's beaked whale (Ziphius cavirostris) (Díaz-Delgado et al. 2016). While adults of $C$. boopis and C. magna are morphologically distinct and found in different body sites, molecular analysis of the $18 \mathrm{~S}$ rRNA gene seems insufficient for reliable species identification. This could be a major restriction mainly for larvae identification.

It is noteworthy that all morphological classifications to date have included Crassicauda spp. in the order Spirurida, superfamily Habronematoidea, family Tetrameridae and subfamily Crassicaudinae (Lambertsen, 1985; Jabbar et al. 2015), while recent phylogenetic analysis based on the $18 \mathrm{~S}$ rRNA gene showed $C$. magna as a member of the Acuarioidea superfamily (Jabbar et al. 2015). The $18 \mathrm{~S}$ rRNA gene shows highly conserved regions, and although this gene is often used for deep phylogenetic relationship investigation, multigene analysis should be performed to refine this phylogenetic analysis.

This fin whale arrived in Belgium probably after a ship-strike in the Bay of Biscay or in the Western English Channel, given the track of the ship and the estimation of period of death. Fin whales are large, long-distance swimmers that often occur far offshore, and not many causes of natural mortality are known, such as predation or starvation which are probably of minor significance. However, decline of major zooplankton populations (Steinberg and Landry, 2017) could lead to poor nutrition and therefore to an increase in the severity of endemic parasitism by compromising disease resistance (Lambertsen, 1992). For this reason, Lambertsen (1986) suggested that diseases like crassicaudiosis may be the most significant mortality factor in large balaenopterid whales (Raga et al. 1997). Further research should be able to collect information on animals infected by parasites especially C. boopis in order to implement a model including the effect of parasitism in calf and adult whale populations.

\section{Conclusion}

Crassicaudiosis is potentially the most significant mortality factor in large balaenopterid and reported 
cases are scarce. Further research is surely needed in order to elucidate the life cycle of the parasite, its taxonomy and impact on whale populations. However, the present report supports the theory that infestation could occur transplacentally or during lactation.

The species is frequently only described from fragments, leading sometimes to uncertainty in their identification. Therefore, molecular biology could be useful in the identification of these specimens with multigene analysis helping to refine identification and phylogenetic analysis.

\section{ACKNOWLEDGEMENTS}

The authors are very grateful to Allison Balin, Jurgen Decraene, Bart De Pauw, Françoise Maréchal, Michael Sarlet and Patrick Vervaet. The authors also thank the volunteers of the veterinary Faculty of Ghent University and the veterinary Faculty of Liege University. They are grateful for the excellent cooperation with the crew of the Premium do Brasil, the local authorities of the city of Ghent, port authorities, the Federal public service health, food chain safety and environment, Citrosuco (and in particular Jean-Pierre Vandecasteele), the Civil Protection Unit, and many others for their role in securing the animal and making the scientific investigation possible.

\section{FINANCIAL SUPPORT}

This research did not receive any specific grant from funding agencies in the public, commercial or not-forprofit sectors. The work was carried out in the framework of the Marine Animals Research and Intervention Network (MARIN), coordinated by the RBINS.

\section{CONFLICT OF INTEREST}

None.

\section{REFERENCES}

Anderson, R. C. (2000). Nematode Parasites of Vertebrates: Their Development and Transmission, 2nd Ed, pp. 650. CABI Publishing, New York, USA.

Balbuena, J. A. and Simpkin, A. (2014). Role of Crassicauda sp. in natural mortality of pantropical spotted dolphins Stenella attenuata: a reassessment. Diseases of Aquatic Organisms 108, 83-89.
Camphuysen, K. and Peet, G. (2006). Whales and Dolphins of the North Sea. Fontaine Uitgevers BV, Fontaine Uitgevers, Kortenhoef, The Netherlands.

Díaz-Delgado, J., Fernández, A., Xuriach, A., Sierra, E., Bernaldo de Quirós, Y., Mompeo, B., Pérez, L., Andrada, M., Marigo, J., Catão-Dias, J. L., Groch, K. R., Edwards, J. F. and Arbelo, M. (2016). Verminous arteritis due to Crassicauda sp. in Cuvier's beaked whales (Ziphius Cavirostris). Veterinary Pathology 53, 1233-1240.

Geraci, J. R. and St. Aubin, D. J. (1987). Effects of parasites on marine mammals. International Fournal for Parasitology 17, 407-414.

Jabbar, A., Beveridge, I. and Bryant, M. S. (2015). Morphological and molecular observations on the status of Crassicauda magna, a parasite of the subcutaneous tissues of the pygmy sperm whale, with a re-evaluation of the systematic relationships of the genus Crassicauda. Parasitology Research 114, 835-841.

Jauniaux, T., Charlier, G., Desmecht, M., Haelters, J., Jacques, T., Losson, B., Van Gompel, J., Tavernier, J. and Coignoul, F. (2000). Pathological findings in two fin whales (Balaenoptera physalus) with evidence of morbillivirus infection. Fournal of Comparative Pathology 123, 198-201. Jauniaux, T., Garcia Hartmann, M., Haelters, J., Tavernier, J. and Coignoul, F. (2002). Echouage de mammifères marins: guide d'intervention et procédures d'autopsie. Annales de Medecine Veterinaire 146, 261-276.

Lambertsen, R. H. (1985). Taxonomy and distribution of a Crassicauda species (Nematoda: Spirurida) infecting the kidney of the common fin whale (Balaenoptera physalus Linné, 1758). Fournal of Parasitology 71, 485-488.

Lambertsen, R. H. (1986). Disease of the common fin whale (Balaenoptera physalus): crassicaudiosis of the urinary system. Fournal of Mammalogy 67, 353-366.

Lambertsen, R. H. (1992). Crassicaudosis: a parasitic disease threatening the health and population recovery of large baleen whales. Revue Scientifique et Technique/Office International des épizooties 11, 1131-1141.

Nadler, S. A., Carreno, R. A., Mejía-Madrid, H., Ullberg, J., Pagan, C., Houston, R. and Hugot, J.-P. (2007). Molecular phylogeny of clade III nematodes reveals multiple origins of tissue parasitism. Parasitology 134, 1421-1442.

Raga, J. A., Balbuena, J. A., Aznar, J. and Fernández, M. (1997). The impact of parasites on marine mammals: a review. Parassitologia 39, 293-296.

Rees, G. (1953). A record of some parasitic worms from whales in the Ross Sea area. Parasitology 43, 27.

Rhode, K. (2005). Marine Parasitology. CABI Publishing, Oxon, UK. Ruys, T. and Soulier, L. (2013). Atlas des Mammifères sauvages d'Aquitaine. C. Nature. Cistude Nature \& LPO Aquitaine, Le Haillan, France.

Sigurjonsson, J. and Vikingsson, G. (1995). Estimation of food consumption by cetaceans in Icelandic and adjacent waters. $\mathrm{AFO}$ ICES Symp. The Role of Marine/Rmammals in the Ecosystem vol. 22, 271-287.

Steinberg, D. K. and Landry, M. R. (2017). Zooplankton and the ocean carbon cycle. Annual Review of Marine Science 9, 413-444. doi: 10.1146/ annurev-marine-010814-015924.

William, F. P., Bernd, W. and Thewissen, J. G. M. (2009). Marine Mammal Species. Elsevier. doi: 10.1016/B978-0-12-373553-9.00291-1. Zucca, P., Di Guardo, G., Pozzi-Mucelli, R., Scaravelli, D. and Francese, M. (2004). Use of computer tomography for imaging of Crassicauda grampicola in a Risso's dolphin (Grampus griseus). Fournal of Zoo and Wildlife Medicine: Official Publication of the American Association of Zoo Veterinarians 35, 391-394. 